\title{
Loss of imprinting control of the IncRNA H19-fetal mitogen IGF2 gene cluster in the decidual microenvironment of patients with idiopathic spontaneous miscarriages
}

\section{Xue Wen}

Jilin University First Hospital

Qi Zhang

Jilin University First Hospital

Lei Zhou

Jilin University First Hospital

Zhaozhi Li

Jilin University First Hospital

\section{Xue Wei}

Jilin University First Hospital

Jiaomei Zhang

Jilin University First Hospital

Hui Li

Jilin University First Hospital

\section{Yongchong Chen}

Jilin University First Hospital

Chao Niu

Jilin university first hospital

Ji Qu

JILIN University first hospital

\section{Min Li}

Jilin university first hospital

Jianting Xu

Jilin University First Hospital

Zijun Xu

Jilin University First Hospital

Xueling Cui

Jilin University

Songling Zhang

Jilin University First Hospital 


\section{Yufeng Wang}

Jilin University First Hospital

\section{Wei Li}

Jilin University First Hospital

Andrew R. Hoffman

Stanford University School of Medicine

\section{Zhonghui Liu}

Jilin University

\section{Jifan Hu ( $\square$ jifan@stanford.edu )}

Stanford University Medical School https://orcid.org/0000-0002-2174-0361

\section{Jiuwei Cui}

Jilin University First Hospital

\section{Research Article}

Keywords: Miscarriage, long noncoding RNA, imprinting, epigenetics, DNA methylation, H3K27 methylation

Posted Date: November 10th, 2021

DOI: https://doi.org/10.21203/rs.3.rs-1044267/v1

License: (c) (i) This work is licensed under a Creative Commons Attribution 4.0 International License. Read Full License 


\section{Abstract}

Miscarriage, the spontaneous loss of a pregnancy before the fetus achieves viability, is a common complication of pregnancy. Decidualization plays a critical role in the implantation of the embryo. To search for molecular factors underlying miscarriage, we explored the role of long noncoding RNAs (IncRNAs) in the decidual microenvironment, where the molecular crosstalk at the feto-maternal interface occurs. By integrating RNA-seq data from recurrent miscarriage patients and decidualized endometrial stromal cells, we identified $\mathrm{H} 19$, a noncoding RNA that exhibits paternally imprinted monoallelic expression in normal tissues, as the most upregulated IncRNA associated with miscarriage. Aberrant upregulation of $\mathrm{H} 19$ IncRNA was observed in decidual tissues derived from patients with spontaneous miscarriage as well as decidualized endometrial stromal cells. The maternally imprinted fetal mitogen Igf2, which is usually reciprocally co-regulated with $\mathrm{H} 19$ in the same imprinting cluster, was also upregulated. Notably, both genes underwent loss of imprinting, as H19 and IGF2 were actively transcribed from both parental alleles in decidual tissues. Mechanistically, this loss of imprinting in decidual tissues was associated with the loss of the H3K27m3 suppression marker in the IGF2 promoter, CpG hypomethylation at the central CTCF binding site in the imprinting control center (ICR) that is located between IGF2 and $\mathrm{H} 19$, and the loss of CTCF-mediated intrachromosomal looping. These data provide the first evidence that aberrant control of the ICR epigenotype-intrachromosomal looping- H19/IGF2 imprinting pathway may be a critical epigenetic risk factor in the abnormal decidualization related to miscarriage.

\section{Introduction}

Miscarriage is the most common complication of pregnancy, affecting $>20 \%$ of recognized pregnancies in fertile women $(1,2)$. Most miscarriages are sporadic and occur prior to the second trimester of pregnancy $(3,4)$. A sub-set of women may suffer from recurrent miscarriage, defined as three or more consecutive miscarriages. This common gynaecological emergency poses significant challenges in regard to fertility and general psychological health.

A successful pregnancy depends upon complex crosstalk between the developmentally competent embryo and the receptive maternal endometrium $(5,6)$. Upon implantation, embryos elicit a complex response in the decidua, characterized by transformation of stromal fibroblasts into secretory, epithelioidlike decidual cells, accompanied by the influx of specialized uterine immune cells and vascular remodeling. Decidual cells produce growth factors and cytokines $(7,8)$, including insulin-like growth factor binding protein1 (IGFBP1) and prolactin (PRL), which are widely used as biomarkers of decidualized cells. Abnormal endometrial receptivity is a key factor leading to implantation failure. However, the molecular factors that regulate this crosstalk in decidualization reactions remains largely uncharacterized.

Long non-coding RNAs (IncRNAs) act as prominent epigenetic factors in normal development and numerous diseases, often by interacting with chromatin remodeling complexes (9-11). However, little is known about the functions of IncRNAs in miscarriage. Decidualization of the endometrium plays an 
essential role for the establishment of a successful pregnancy. In order to identify key RNA molecules that mediate the molecular crosstalk at the feto-maternal interface, we integrated two RNA transcriptome sequencing datasets from RSA patients and decidualized human endometrial stromal cells. Notably, we identified $H 19$, a paternally imprinted IncRNA $(12,13)$, and its reciprocally co-regulated gene, the maternally imprinted fetal mitogen Igf2 $(14,15)$, were highly upregulated in decidual tissues. Aberrant DNA methylation in the $\mathrm{H} 19$ imprinting control center (ICR) correlates with the risk of abortion (16). Decidual tissues derived from patients with spontaneous miscarriage showed that H19-IGF2 expression was significantly increased in decidual tissues compared with healthy decidual tissues, suggesting abnormal H19-IGF2 expression in decidualization was directly related to recurrent miscarriage. Allelic analysis revealed loss of $H 19$ and IGF2 imprinting in decidual tissues of patients who had suffered a miscarriage. These data implicate the involvement of abnormal H19/IGF2 imprinting in the decidual microenvironment related to miscarriage.

\section{Results}

\section{Identification of H19 as miscarriage-associated IncRNA}

To search for key factors that might be involved in the feto-maternal regulatory crosstalk, we integrated two RNA transcriptome sequencing datasets: GSE178535 (RNA-seq data from three RSA patients and three healthy control subjects) and GSE160702 (RNA-seq data from decidualized human endometrial stromal cells) (17). The integration using the VENN program identified a total of 745 differentially expressed genes (Figs.1A), including 673 protein-coding genes and 62 IncRNAs. The Kyoto Encyclopedia of Genes and Genomes (KEGG) pathway analysis showed the association with cytokine-cytokine receptor interaction, pathways in cancer, basal cell carcinoma, proteoglycans in cancer, signaling pathways in the regulation of stem cell pluripotency (Fig.1B, Table S2).

Among 62 identified IncRNAs (log2FoldChange>2, VALUE<0.001), H19 was the most upregulated IncRNA (Figs.1C, Table S3). H19 is a well-known imprinted IncRNA. In most tissues, H19 is expressed only from the maternal allele, while the paternal allele is imprinted and not expressed.

\section{Dysregulation of H19 in patients with idiopathic spontaneous miscarriages}

We then quantitated the expression of $\mathrm{H} 19$ in decidual tissues collected from 32 patients with firsttrimester miscarriage. For comparison, decidual tissues were also collected from 57 healthy adult women at 7-10 weeks of gestation who were undergoing early pregnancy termination. Using RT-qPCR, we found that the expression of $\mathrm{H} 19$ was significantly higher in decidual tissues from the patients with spontaneous miscarriages than in decidua of healthy female subjects (Fig.2A, $p<0.05$ ).

The $\mathrm{H} 19$ gene is located in an imprinting cluster on human chromosome 11 and is co-regulated with IGF2, a gene that encodes a mitogen that is required for normal fetal growth. Therefore, we also quantitated the mRNA abundance of IGF2 in decidual tissues using quantitative PCR and found that, like 
H19, IGF2 was also significantly upregulated in decidual tissues derived from patients who had suffered a miscarriage (Fig.2B, $p<0.01$ ).

\section{Loss of genomic imprinting in decidual tissues from miscarriage patients}

To examine the status of $H 19$ and IGF2 imprinting in decidual tissues, we genotyped genomic DNA using two single nucleotide polymorphisms (SNPs) in H19 and IGF2. Heterozygous SNPs were used to distinguish the two parental alleles, and the imprinting status was examined in those tissues that were SNP-informative. Twenty-one of the decidual tissues derived from patients who had suffer a miscarriage were informative for $\mathrm{H} 19$ heterozygosity and 20 were informative for IGF2 heterozygosity. We found that the H19/IGF2 imprinting was lost in 39\% (11/28) of H19/IGF2 informative decidual tissues from the miscarriage cases (Fig.3A). Among them, 2 out of 21 samples (9.5\%) showed the loss of $H 19$ imprinting, and 7 out of 20 samples (35\%) exhibited IGF2 LOI. Two samples that were H19/IGF2 informative also showed the loss of imprinting of both H19 and IGF2 (Table 1).

As an example, the decidual tissue from Control \#13 showed normal imprinting of $H 19$ (maintenance of imprinting, MOI) (Fig.3B, panel 2). The genomic DNA carried both the " $A$ " and " $C$ " alleles, but the cDNA showed the exclusive expression of the " $A$ " allele. The " $C$ " allele was silenced. The decidual tissues from two cases (\#U18 and \#M22) were also informative for the SNP (Fig.3B, panels 3-4). However, both the "A" and " $\mathrm{C}$ " alleles were detected in their cDNA samples, demonstrating loss of imprinting (LOI) (Fig.3B).

Similarly, the genotyping of a SNP at the 3'-UTR of IGF2 showed the presence of the "C/T" alleles. In normal informative decidual tissues, only the " $\mathrm{T}$ " allele was expressed (Fig.3C, top right panel). However, in two cases of miscarriage (U11, M22), the normally silenced $\mathrm{C}$ allele was expressed in decidual tissues (Fig.3C, right panels 2-3).

Loss of IGF2/H19 imprinting is an early oncogenic event being detected in tumor-paired adjacent normal tissues (18). Thus, we also examined the allelic expression of IGF2/H19 in decidual samples of control subjects. Notably, we also detected the presence of IGF2/H19 LOI in the decidua of some control subjects (Tables S4-S5), suggesting epigenetic vulnerability in the decidual microenvironment of early embryo development.

\section{Loss of genomic imprinting following decidualization in primary cells}

In vitro cell-induced decidualization has provided a good model for studying the complex process of implantation $(11,19,20)$. We thus examined if genomic imprinting would be altered following induction of decidualization in human U29 primary endometrial stromal cells that kept normal H19-IGF2 imprinting (MOI). We induced decidualization in vitro by treating U29 cells with $10 \mathrm{nM} \mathrm{E2,} 1 \mu \mathrm{M}$ P4 and $0.5 \mathrm{mM} 8-\mathrm{Br}-$ cAMP for $96 \mathrm{~h}$. Following the treatment, cell morphology changed from elongated to rounded, and proliferation increased (Fig.4A). The treated cells exhibited elevated expression of decidualization markers PRL and IGFBP1 (Fig.4B. H19 and IGF2 were significantly upregulated in the decidualized cells (Fig.4C). 
The untreated cells maintained normal imprinting, with only the "C" allele expressed (Fig.4D, right top panel). The imprinting status of $\mathrm{H} 19$ was maintained in the in vitro induced decidualized cells (right bottom panel), but IGF2 imprinting was lost, with both parental alleles (C/T) expressed in the decidualized cells (Fig.4E, right bottom panel). IGF2 and H19 expression are normally tightly coordinated and reciprocally controlled by an "enhancer competition" mechanism [64]. The data from these treated primary endometrial stromal cells, however, suggest that the imprinting control of IGF2 and $H 19$ can be uncoupled.

\section{Loss of imprinting is associated with aberrant histone H3K27 methylation}

We then examined the epigenetic mechanisms underlying the loss of imprinting by focusing on the histone 3 lysine 27 (H3K27) suppression marker in the IGF2 promoter (Fig.5A) (21). Using a ChIP assay with antibodies specific for H3K27me3, we found that H3K27 methylation in the first two IGF2 imprinted promoters (hP2, hP3) was significantly reduced in 8-Br-cAMP-treated primary U29 decidual cells, where the IGF2 imprinting status was lost (Fig.5B). No significant change of the H3K27me3 suppression mark was observed in the hP4 promoter.

\section{Aberrant H3K27 imprinting is accompanied with the loss of intrachromosomal looping}

The status of histone 3 lysine 27 (H3K27) is determined by the CTCF-orchestrated intrachromosomal looping $(22,23)$. CTCF binds to unmethylated DNA motifs in the imprinting control region (ICR) located between the $\mathrm{H} 19$ and IGF2 genes, and orchestrates the formation of an intrachromosomal loop, where polycomb repressive complex 2 (PCR2) is recruited via the docking factor SUZ12, leading allelic H3K27 methylation which then silences the imprinted allele (24).

We used chromosome conformation capture (3C) methodology to examine the chromatin threedimensional (3D) structure surrounding the IGF2/19 locus, with the focus on the CTCF-binding site in the ICR (25). As expected, we detected an intrachromosomal loop structure between the ICR-enhancers and ICR-IGF2 promoters in untreated U29 primary decidual cells (Fig.6A). The 3C products were purified and DNA sequencing confirmed the loop joint separated by the Bgl2/BamH1, Bgl2/Bgl2, BamH1/BamH1 ligation sites (Fig.6B). However, after induced decidualization in vitro with 8-Br-cAMP, all three intrachromosomal loops were abolished (Fig.6C), in parallel with the loss of IGF2 imprinting. As was previously reported in cancer cells with LOI (22), CTCF-orchestrated intrachromosomal looping may be essential for maintaining normal imprinting of IGF2 in decidual tissues.

\section{Loss of imprinting is associated with de novo DNA methylation in the imprinting control region}

The methylation status of $\mathrm{CpG}$ islands in the imprinting control region (ICR) located upstream of the $\mathrm{H} 19$ gene plays a pivotal role in the formation of intrachromosomal loops. The ICR contains seven CTCF binding sites. Among them, the $6^{\text {th }}$ CTCF is differentially methylated (26) and serves as a CTCF "boundary insulator" (27). Specific binding of CTCF to the unmethylated maternal allele creates a physical boundary that blocks the interaction of downstream enhancers with the IGF2 promoters and 
thus silences the maternal IGF2 allele. On the other hand, methylation of the ICR prevents CTCF binding and permits expression of IGF2 and silencing of $H 19$ from the paternal allele. As a result, differential methylation at the CTCF binding sites ensures the reciprocal imprinting of these two neighboring genes (18).

We examined allele-specific DNA methylation in decidual tissues that were informative for two SNPs in the ICR and one SNP in the H19 promoter (Fig.7A). The status of CpG DNA methylation was examined using sodium bisulfite sequencing. After converting the unmethylated cytosines into uracils by sodium bisulfite, the ICR and $\mathrm{H} 19$ promoter regions were amplified with DNA methylation-specific primers, and cloned into a pJet vector for DNA sequencing. Case \#M22 tissue derived from a patient with miscarriage, was homozygous for two SNPs, and therefore we were not be able to distinguish the two parental alleles. However, we detected hyper-methylation in the ICR and the H19 promoter (Fig.7B, top panel). Case U11, which was heterozygous for the ICR SNP, had a hyper-methylated "AA" allele and an increased DNA methylation in the "AG" allele (36.5\%)(left top panel). As expected, a typical semi-methylated pattern was observed in control \#C4 that had normal mono-allelic expression of H19 and IGF2 (Fig.S2).

We also observed increased CpG DNA methylation at the ICR CTCF6 site and H19 promoter $(19.2 \%$ and $63.1 \%$ ) in decidualized cells, as compared with the control cells (4.6\% and 47\%)(Fig.S3). These data suggest that aberrant imprinting of H19/IGF2 may be associated with CpG DNA epimutations in the ICR region.

\section{Discussion}

The molecular mechanisms underlying the spontaneous loss of a pregnancy are unknown(28). Decidualization plays a critical role in the implantation of the embryo through a regulatory network that coordinates trophoblast invasion of the maternal decidua-myometrium and remodeling of maternal uterine spiral arteries $(29,30)$. Many factors, including locally secreted cytokines and growth factors, are involved in this complicated network. We have identified the IncRNA H19 as the most upregulated RNA molecule in decidual tissue, where the molecular crosstalk at the feto-maternal interface occurs. $\mathrm{H} 19$ is also significantly upregulated in the decidua derived from patients with miscarriage. IGF2, a gene which encodes an important fetal mitogen, is located at the same chromosomal locus, and it is also increased in the decidua in patients who have suffered a miscarriage. In most normal tissues, the H19/IGF2 locus is imprinted. In this study, we demonstrate that there is loss of H19 and IGF2 imprinting in decidual tissues of miscarriage patients. Loss of imprinting also occurs following induced decidualization in primary endometrial stromal cells. These data suggest that dysregulation of IGF2/H19 imprinting may be related to poor decidualization in patients with miscarriage. Mechanistically, we show that this aberrant imprinting in decidual tissues was associated with the loss of the H3K27m3 suppression marker as well as the loss of intrachromosomal looping and $\mathrm{CpG}$ demethylation in the imprinting control center (ICR). These studies suggest the involvement of abnormal H19/IGF2 epigenetic regulation in the decidual microenvironment, which may be a risk factor for the development of early unexplained spontaneous abortion (Fig.7C). 
Both the maternal and paternal genomes are necessary for normal embryogenesis and fetal development $(31,32) . H 19$ is a maternally-expressed imprinted gene and its transcription gives rise to a fetal IncRNA that also functions as a precursor to miR675 (33), which negatively affects cell proliferation and tumor metastasis (34). H19 is abundantly expressed prior to implantation or shortly thereafter, and its expression is specifically confined to progenitor cells of the placenta and extraembryonic tissues $(35,36)$. $\mathrm{H} 19$ is expressed coordinately with its neighboring gene $\lg f 2$, a gene that plays a key role in regulating feto-placental development $(37,38)$. Genomic deletion of Igf2 causes placental and fetal growth restriction. In contrast, overexpression of Igf2 induces placental and fetal overgrowth via paracrine and/or autocrine IGF pathways. The serum levels of IGF-II have been positively linked to infant birth weight. H19 and Igf2 regulate embryonic development $(39,40)$. The allelic expression of IGF2/ H19 is coordinately controlled by a differentially methylated imprinting control region (ICR) in the upstream of the H19 promoter $(18,41)$. In this study, we demonstrate that both H19 and IGF2 are upregulated in decidual tissues of miscarriage patients. Moreover, there is loss of imprinting of both genes in decidual tissues. Our study suggests that aberrant allelic expression of H19/IGF2 genes may lead to abnormal fetal development and spontaneous miscarriage in these patients.

Major epigenetic events take place in the embryo both in pre-implantation development and in postimplantation stages, including the genome-wide resetting of imprints in the PGCs $(42,43)$. Aberrant methylation of imprinted genes correlates with the risk of abortion (16). Specifically, CpG hypomethylation in H19 ICR is correlated with recurrent pregnancy loss (44). As a result, the periconceptional stage is very sensitive to environmental stressors, leading to epigenetic disturbances. Our data also suggest that aberrant resetting of imprints in pre-implantation development and postimplantation stages may be mechanistically associated with the onset of early spontaneous miscarriage.

In summary, this study demonstrates that loss of H19/IGF2 imprinting in decidua may be a critical risk factor related to early miscarriage. Increased abundance of H19 IncRNA in association with the high abundance of IGF-II mitogen in the human fetal decidua may alter normal fetal-placental development. Dynamic regulation of the H19/IGF2 cluster is critical for normal fetal growth and development. It is noteworthy that aberrant imprinting can be epigenetically corrected (18). It would be interesting to explore whether epigenetic targeting of the H19/IGF2 epimutation may provide a novel alternative strategy for the prevention and therapy of recurrent miscarriage.

\section{Materials And Methods}

\section{Identification of miscarriage-associated IncRNAs using RNA-Seq data}

To identify miscarriage-associated IncRNAs, we downloaded two datasets (GSE178535 and GSE160702) from the NIH GEO database website. The GSE178535 dataset contained the RNA-seq data of decidual tissues from three recurrent miscarriage patients and three healthy control subjects (https://www.ncbi.nlm.nih.gov/geo/query/acc.cgi?acc=GSE178535). 
The GSE160702 dataset was the RNA-seq data from decidualized human endometrial stromal cells (ESCs) (https://www.ncbi.nlm.nih.gov/geo/query/acc.cgi?acc=GSE160702). The in vitro decidualization of ESCs was induced using differentiation media containing $0.3 \mathrm{mM}$ dibutyryl cAMP, $1 \mu \mathrm{M}$ medroxyprogesterone 17-acetate and $10 \mathrm{nM} \beta$-estradiol. Decidualized cells were used for RNA-seq (17).

Differentially expressed RNAs were calculated as the log2-transformed gene expression values (Fold Change). The Kyoto Encyclopedia of Genes and Genomes (KEGG) pathway analysis (KEGG_PATHWAY) was carried out using DAVID Bioinformatics Resources 6.8 (https://david.ncifcrf.gov). Hierarchical Cluster Heatmap was generated using HIPLOT (https://hiplot.com.cn). The above two RNA-Seq datasets were merged using the VENN program (http://bioinformatics.psb.ugent.be/webtools/Venn/). Venn diagrams were constructed to visualize the overlap RNAs between the two datasets. The overlapping RNAs with the fold-change $>2$ and $p<0.001$ were chosen for further functional characterization.

\section{Human decidual samples}

Decidual tissue samples were collected from The First Hospital of Jilin University between 2017-2019. A total of 32 decidual tissues were collected from women with unexplained miscarriage. In addition, 57 decidual samples were obtained as the control group from healthy adult women at 7-10 weeks of gestation undergoing legal elective termination. Ethical approval for this study was provided by the Research Ethics Board of the First Hospital of Jilin University, and written informed consent was obtained from all patients prior to sample collection.

\section{Culture of human primary endometrial stromal cells}

Primary endometrial stromal cells were cultured from U29 decidual tissues that were H19-IGF2 informative and kept normal imprinting. Fresh tissues were cut into approximately $2 \mathrm{~mm}^{3}$ fragments, washed in DMEM (high glucose; Sigma), and directly cultured at $37^{\circ} \mathrm{C}$ in $5 \% \mathrm{CO} 2$ by attaching to the substratum in a 10-cm dish with complete medium consisting of DMEM medium (Sigma, MO) supplemented with $10 \%(\mathrm{v} / \mathrm{v})$ fetal bovine serum (Sigma, MO), $100 \mathrm{U} / \mathrm{ml}$ of penicillin sodium, and $100 \mu \mathrm{g} / \mathrm{ml}$ of streptomycin sulfate (Invitrogen, CA). After approximately 12 days in culture, cells migrated out from the edges. Migrating cells were collected with $0.1 \%$ trypsin and $0.25 \mathrm{mM}$ EDTA and passaged for allelic study and in vitro decidualization assays (Fig.S1).

\section{In vitro decidualization}

In vitro artificially-induced decidualization was performed following the method as described (19). Briefly, U29 primary endometrial stromal cells were cultured in complete medium containing $10 \mathrm{nM} \mathrm{E2,} 1 \mu \mathrm{M} \mathrm{P} 4$ and $0.5 \mathrm{mM}$ 8-Br-cAMP. Culture medium was changed every 2 days. Cells were harvested for subsequent experiments $96 \mathrm{~h}$ after the treatment.

\section{RT-PCR quantitation}


Decidual tissues and cells were collected and total RNA was extracted by TRIzol reagent (Sigma,CA) and stored at $-80^{\circ} \mathrm{C}$. cDNA was synthesized using RNA reverse transcriptase (Invitrogen, CA), and target amplification was performed with a Bio-Rad Thermol Cycler. PCR of 1 cycle at $95^{\circ} \mathrm{C}$ for $2 \mathrm{~min}, 32 \mathrm{cycles}$ at $95^{\circ} \mathrm{C}$ for $15 \mathrm{sec}, 60^{\circ} \mathrm{C}$ for $15 \mathrm{sec}$, and $72^{\circ} \mathrm{C}$ for $15 \mathrm{sec}$, and 1 cycle at $72^{\circ} \mathrm{C}$ for $10 \mathrm{~min} ; \beta$-actin was used as the control. Quantitative real-time PCR was performed using SYBR GREEN PCR Master (Applied Biosystems, USA); the threshold cycle (Ct) values of target genes were assessed by quantitative PCR in triplicate using a sequence detector (ABI Prism 7900HT; Applied Biosystems) and were normalized over the $\mathrm{Ct}$ of the $\beta$-actin control. Primers used for PCR quantitation are listed in Table S1.

\section{Allelic expression of IGF2 and H19}

Genomic DNA and total RNA extraction from decidual tissues and cDNA synthesis were performed as previously described. Decidual tissues were first genotyped for heterozygosity of SNPs in IGF2 exon 9 and $\mathrm{H} 19$ exon 5 (Fig2A). Target amplification was performed with a Bio-Rad Thermol Cycler. PCR of 1 cycle at $95^{\circ} \mathrm{C}$ for $2 \mathrm{~min}, 32$ cycles at $95^{\circ} \mathrm{C}$ for $15 \mathrm{sec}, 60^{\circ} \mathrm{C}$ for $15 \mathrm{sec}$, and $72^{\circ} \mathrm{C}$ for $15 \mathrm{sec}$, and 1 cycle at $72^{\circ} \mathrm{C}$ for 10 min using primers specific for two polymorphic restriction enzymes (Apal, Alul) in the last exon of human IGF2 and H19 exon 5. To determine the status of IGF2 imprinting, the amplified products were sequenced by Comate Bioscience Co, Ltd (Changchun, China). Decidual tissues that maintain normal imprinting (MOI) express a single parental allele, while the LOI showed biallelic expression of IGF2 and H19. PCR primers used for IGF2 imprinting are listed in Supplementary Table S1.

\section{DNA methylation analysis}

Genomic DNA collected from tissues or cells, using dBIOZOL Genomic DNA Extraction Reagent (BioFlux, BSC16M1) following the manufacturer's instructions. DNA was treated with EZ DNA Methylation-Gold ${ }^{\mathrm{TM}}$ Kit (ZYMO RESEARCH, D5005), and PCR was performed using DNA methylationspecific primers designed for the promoter of $H 19$ and CTCF binding sites (Table S1). To examine the status of DNA methylation in every CpG site, the amplified PCR DNAs were cloned into pJET1.2/blunt cloning vector (Thermo, K1231) and transformed into TOP10. Plasmid DNA was collected by Wizard $^{\circledR}$ Plasmid DNA Purification kit (Promega, A1223) and sequenced.

\section{Chromosome conformation capture (3C)}

The $3 \mathrm{C}$ assay was performed to determine long-range intrachromosomal interactions as previously described $(23,45-47)$. Briefly, $1.0 \times 10^{7}$ cells were cross-linked with $2 \%$ formaldehyde and lysed with cell lysis buffer (10 mM Tris [pH 8.0], $10 \mathrm{mM} \mathrm{NaCl}, 0.2 \% \mathrm{NP}-40$, supplemented with protease inhibitors). Nuclei were collected, suspended in $1 \times$ restriction enzyme buffer. An aliquot of nuclei $\left(2 \times 10^{6}\right)$ was digested with $800 \mathrm{U}$ of restriction enzyme BamH1 / Bgl2 at $37^{\circ} \mathrm{C}$ overnight. After stopping the reaction by adding $1.6 \%$ SDS and incubating the mixture at $65^{\circ} \mathrm{C}$ for $20 \mathrm{~min}$, chromatin DNA was diluted with NEB ligation reaction buffer, and $2 \mu \mathrm{g}$ DNA was ligated with $4000 \mathrm{U}$ of T4 DNA ligase (New England BioLabs, $\mathrm{CA}$ ) at $16^{\circ} \mathrm{C}$ for $4 \mathrm{~h}$ (final DNA concentration, $2.5 \mu \mathrm{g} / \mathrm{ml}$ ). After treatment with $10 \mathrm{mg} / \mathrm{ml}$ proteinase $\mathrm{K}$ at $65^{\circ} \mathrm{C}$ for $4 \mathrm{~h}$ to reverse cross-links and with $0.4 \mu \mathrm{g} / \mathrm{ml}$ RNase A for $30 \mathrm{~min}$ at $37^{\circ} \mathrm{C}$, DNA was extracted 
with phenol-chloroform, ethanol precipitated and detected by PCR amplification of the ligated DNA products. 3C PCR products were cloned and sequenced to validate the intrachromosomal interactions by assessing for the presence of the $\mathrm{BamH} \mathrm{I/Bgl} \mathrm{II} \mathrm{ligation} \mathrm{site.} \mathrm{The} 3 \mathrm{C}$ interaction was quantitated by qPCR and was standardized over the $3 \mathrm{C}$ ligation control. For comparison, the relative $3 \mathrm{C}$ interaction was calculated by setting the control as 1 . Primers used for $3 \mathrm{C}$ assay are listed in Supplementary Table S1.

\section{Histone methylation by chromatin immunoprecipitation (ChIP) assay}

A ChIP assay was used to quantitate the status of histone modifications, following the manufacturer's protocol (Upstate Biotechnology, Lake Placid, NY, USA). Briefly, $1.0 \times 10^{7}$ cells were fixed with $1 \%$ formaldehyde and then sonicated for $180 \mathrm{~s}$ (10 s on and $10 \mathrm{~s}$ off) on ice with a sonicator with a 2-mm microtip at $40 \%$ output control and $90 \%$ duty cycle settings. The sonicated chromatin was collected by centrifugation, aliquoted and stored at $-80^{\circ} \mathrm{C}$. Protein A/G Magnetic Beads and a specific anti-trimethylhistone H3 (Lys27) antibody (Merck Millipore, Darmstadt, Germany) were incubated with rotation for $30 \mathrm{~min}$ at room temperature. The sonication supernatant and beads were incubated with antibody at $4^{\circ} \mathrm{C}$ on a rotating rack for 4-16 hours or overnight. To reduce the ChIP background, we modified the manufacturer's protocol by adding two washing steps following immunoprecipitation. As previously reported (23), anti-IgG was used as the ChIP control in parallel with testing samples. Precipitated DNA was subjected to qPCR and expressed as fold-enrichment compared to the lgG chromatin input.

\section{Statistical Analysis}

The experimental data are expressed as mean \pm SD and were performed in triplicate. Data were analyzed using SPSS software (version 16.0; SPSS, IL). Student's t test or one-way ANOVA (Bonferroni test) was used to compare statistical differences for variables among groups. Results were considered statistically significant at $p<0.05$.

\section{Declarations}

\section{Ethics approval and consent to participate}

Ethical approval for this study was provided by the Research Ethics Board of the First Hospital of Jilin University, and written informed consent was obtained from all patients before sample collection.

\section{Consent for publication}

Not applicable.

\section{Availability of date and materials}

GSE178535 and GSE160702 downloaded from the NIH GEO database website. The GSE178535 dataset contained the RNA-seq data of decidual tissues from three recurrent miscarriage patients and three healthy control subjects (https://www.ncbi.nlm.nih.gov/geo/query/acc.cgi?acc=GSE178535). 
The GSE160702 dataset was the RNA-seq data from decidualized human endometrial stromal cells (ESCs) (https://www.ncbi.nlm.nih.gov/geo/query/acc.cgi?acc=GSE160702).

\section{Competing interests}

The authors declare no competing interests.

\section{Acknowledgments/Funding}

This work was supported by the National Key R\&D Program of China (2018YFA0106902), National Natural Science Foundation of China (82050003, 81900701, 31430021, 81874052, 81672275, 31871297, $81670143,81900701,32000431)$, the Key Project of Chinese Ministry of Education grant (311015), the National Basic Research Program of China (973 Program)(2015CB943303), Nation Key Research and Development Program of China grant (2016YFC13038000), Research on Chronic Noncommunicable Diseases Prevention and Control of National Ministry of Science and Technology (2016YFC1303804), National Health Development Planning Commission Major Disease Prevention and Control of Science and Technology Plan of Action, Cancer Prevention and Control (ZX-07-C2016004), Natural Science Foundation of Jilin Province (20200801046GH, 20150101176JC, 20180101117JC, 20130413010GH), Provincial Science Fund of Jilin Province Development and Reform Commission (2014N147 and 2017C022), the 10th Youth Fund of First Hospital of Jilin University (JDYY102019034, JDYY102019043); and the Biomedical Research Service of the Department of Veterans Affairs (BX002905).

\section{Authors' contributions}

J.F.H., J.C., and Z.L. conceived and designed the study; W.L., S.Z., X.C., and Y.W. supervised the project; W.X. and Q.Z. performed most of the experiments and organized the data; L.Z., Z.L., X.W., J.Z., H.L., Y.C., C.N., J.Q., M.L., and J.X. conducted cell assays; J.F.H. wrote the paper; A.R.H. edited the manuscript. All authors read and approved the manuscript.

\section{References}

1. How, J., Leiva, O., Bogue, T., Fell, G.G., Bustoros, M.W., Connell, N.T., Connors, J.M., Ghobrial, I.M., Kuter, D.J., Mullally, A.et al. (2020) Pregnancy outcomes, risk factors, and cell count trends in pregnant women with essential thrombocythemia. Leuk Res, 98, 106459.

2. Garrido-Gimenez, C. and Alijotas-Reig, J. (2015) Recurrent miscarriage: causes, evaluation and management. Postgrad Med J, 91, 151-162.

3. Pinar, M.H., Gibbins, K., He, M., Kostadinov, S. and Silver, R. (2018) Early Pregnancy Losses: Review of Nomenclature, Histopathology, and Possible Etiologies. Fetal Pediatr Pathol, 37, 191-209.

4. McPherson, E. (2016) Recurrence of stillbirth and second trimester pregnancy loss. Am J Med Genet A, 170A, 1174-1180. 
5. Ticconi, C., Pietropolli, A., Di Simone, N., Piccione, E. and Fazleabas, A. (2019) Endometrial Immune Dysfunction in Recurrent Pregnancy Loss. International journal of molecular sciences, 20.

6. Okada, H., Tsuzuki, T. and Murata, H. (2018) Decidualization of the human endometrium. Reprod Med Biol, 17, 220-227.

7. Peter Durairaj, R.R., Aberkane, A., Polanski, L., Maruyama, Y., Baumgarten, M., Lucas, E.S., Quenby, S., Chan, J.K.Y., Raine-Fenning, N., Brosens, J.J.et al. (2017) Deregulation of the endometrial stromal cell secretome precedes embryo implantation failure. Mol Hum Reprod, 23, 478-487.

8. Gibson, D.A., Simitsidellis, I., Cousins, F.L., Critchley, H.O. and Saunders, P.T. (2016) Intracrine Androgens Enhance Decidualization and Modulate Expression of Human Endometrial Receptivity Genes. Sci Rep, 6, 19970.

9. Chen, J., Wang, Y., Wang, C., Hu, J.F. and Li, W. (2020) LncRNA Functions as a New Emerging Epigenetic Factor in Determining the Fate of Stem Cells. Front Genet, 11, 277.

10. Patty, B.J. and Hainer, S.J. (2020) Non-Coding RNAs and Nucleosome Remodeling Complexes: An Intricate Regulatory Relationship. Biology (Basel), 9.

11. Huang, H., Sun, J., Sun, Y., Wang, C., Gao, S., Li, W. and Hu, J.F. (2019) Long noncoding RNAs and their epigenetic function in hematological diseases. Hematological oncology, 37, 15-21.

12. Pope, C., Mishra, S., Russell, J., Zhou, Q. and Zhong, X.B. (2017) Targeting H19, an Imprinted Long Non-Coding RNA, in Hepatic Functions and Liver Diseases. Diseases, $\mathbf{5}$.

13. MacDonald, W.A. and Mann, M.R.W. (2020) Long noncoding RNA functionality in imprinted domain regulation. PLoS Genet, 16, e1008930.

14. Marasek, P., Dzijak, R., Studenyak, I., Fiserova, J., Ulicna, L., Novak, P. and Hozak, P. (2015) Paxillindependent regulation of IGF2 and H19 gene cluster expression. J Cell Sci, 128, 3106-3116.

15. Kasprzak, A. and Adamek, A. (2019) Insulin-Like Growth Factor 2 (IGF2) Signaling in Colorectal Cancer-From Basic Research to Potential Clinical Applications. International journal of molecular sciences, 20.

16. Cannarella, R., Crafa, A., Condorelli, R.A., Mongioi, L.M., La Vignera, S. and Calogero, A.E. (2021) Relevance of sperm imprinted gene methylation on assisted reproductive technique outcomes and pregnancy loss: a systematic review. Syst Biol Reprod Med, 67, 251-259.

17. Deryabin, P., Domnina, A., Gorelova, I., Rulev, M., Petrosyan, M., Nikolsky, N. and Borodkina, A. (2021) "All-In-One" Genetic Tool Assessing Endometrial Receptivity for Personalized Screening of Female Sex Steroid Hormones. Front Cell Dev Biol, 9, 624053. 
18. Hu, J.F. and Hoffman, A.R. (2016) In Holland, K. (ed.), DNA Methylation: Patterns, Functions and Roles in Disease, pp. 91-110.

19. Marquardt, R.M., Lee, K., Kim, T.H., Lee, B., DeMayo, F.J. and Jeong, J.W. (2020) Interleukin-13 receptor subunit alpha-2 is a target of progesterone receptor and steroid receptor coactivator- 1 in the mouse uterusdagger. Biol Reprod, 103, 760-768.

20. Rytkonen, K.T., Erkenbrack, E.M., Poutanen, M., Elo, L.L., Pavlicev, M. and Wagner, G.P. (2019) Decidualization of Human Endometrial Stromal Fibroblasts is a Multiphasic Process Involving Distinct Transcriptional Programs. Reprod Sci, 26, 323-336.

21. Li, T., Hu, J.F., Qiu, X., Ling, J., Chen, H., Wang, S., Hou, A., Vu, T.H. and Hoffman, A.R. (2008) CTCF regulates allelic expression of Igf2 by orchestrating a promoter-polycomb repressive complex-2 intrachromosomal loop. Molecular and cellular biology, 28, 6473-6482.

22. Li, T., Chen, H., Li, W., Cui, J., Wang, G., Hu, X., Hoffman, A.R. and Hu, J. (2014) Promoter histone H3K27 methylation in the control of IGF2 imprinting in human tumor cell lines. Hum Mol Genet, 23, 117128.

23. Zhao, X., Liu, X., Wang, G., Wen, X., Zhang, X., Hoffman, A.R., Li, W., Hu, J.F. and Cui, J. (2016) Loss of insulin-like growth factor II imprinting is a hallmark associated with enhanced chemo/radiotherapy resistance in cancer stem cells. Oncotarget, 7, 51349-51364.

24. Hu, J.F. and Hoffman, A.R. (2014) Chromatin looping is needed for iPSC induction. Cell Cycle, 13, 1-2. 25. Ulaner, G.A., Yang, Y., Hu, J.F., Li, T., Vu, T.H. and Hoffman, A.R. (2003) CTCF binding at the insulin-like growth factor-II (IGF2)/H19 imprinting control region is insufficient to regulate IGF2/H19 expression in human tissues. Endocrinology, 144, 4420-4426.

26. Bartolomei, M.S., Webber, A.L., Brunkow, M.E. and Tilghman, S.M. (1993) Epigenetic mechanisms underlying the imprinting of the mouse $\mathrm{H} 19$ gene. Genes \& development, 7, 1663-1673.

27. Lewis, A. and Murrell, A. (2004) Genomic imprinting: CTCF protects the boundaries. Curr Biol, 14, R28428-28426.

28. O'Connor, B.B., Pope, B.D., Peters, M.M., Ris-Stalpers, C. and Parker, K.K. (2020) The role of extracellular matrix in normal and pathological pregnancy: Future applications of microphysiological systems in reproductive medicine. Exp Biol Med (Maywood), 245, 1163-1174.

29. Conrad, K.P., Rabaglino, M.B. and Post Uiterweer, E.D. (2017) Emerging role for dysregulated decidualization in the genesis of preeclampsia. Placenta, 60, 119-129.

30. Vinketova, K., Mourdjeva, M. and Oreshkova, T. (2016) Human Decidual Stromal Cells as a Component of the Implantation Niche and a Modulator of Maternal Immunity. J Pregnancy, 2016, 
8689436.

31. Crespi, B.J. (2019) Why and How Imprinted Genes Drive Fetal Programming. Front Endocrinol (Lausanne), 10, 940.

32. Zhang, K. and Smith, G.W. (2015) Maternal control of early embryogenesis in mammals. Reprod Fertil Dev, 27, 880-896.

33. Cai, X. and Cullen, B.R. (2007) The imprinted H19 noncoding RNA is a primary microRNA precursor. RNA, 13, 313-316.

34. Matouk, I.J., Halle, D., Raveh, E., Gilon, M., Sorin, V. and Hochberg, A. (2016) The role of the oncofetal H19 IncRNA in tumor metastasis: orchestrating the EMT-MET decision. Oncotarget, 7, 3748-3765.

35. Hanna, C.W. (2020) Placental imprinting: Emerging mechanisms and functions. PLoS Genet, 16, e1008709.

36. Nordin, M., Bergman, D., Halje, M., Engstrom, W. and Ward, A. (2014) Epigenetic regulation of the Igf2/H19 gene cluster. Cell Prolif, 47, 189-199.

37. Blyth, A.J., Kirk, N.S. and Forbes, B.E. (2020) Understanding IGF-II Action through Insights into Receptor Binding and Activation. Cells, 9.

38. Fowden, A.L. (2003) The insulin-like growth factors and feto-placental growth. Placenta, 24, 803-812.

39. Ratajczak, M.Z. (2012) Igf2-H19, an imprinted tandem gene, is an important regulator of embryonic development, a guardian of proliferation of adult pluripotent stem cells, a regulator of longevity, and a 'passkey' to cancerogenesis. Folia Histochem Cytobiol, 50, 171-179.

40. Argyraki, M., Damdimopoulou, P., Chatzimeletiou, K., Grimbizis, G.F., Tarlatzis, B.C., Syrrou, M. and Lambropoulos, A. (2019) In-utero stress and mode of conception: impact on regulation of imprinted genes, fetal development and future health. Hum Reprod Update, 25, 777-801.

41. Matouk, I.J., Halle, D., Gilon, M. and Hochberg, A. (2015) The non-coding RNAs of the H19-IGF2 imprinted loci: a focus on biological roles and therapeutic potential in Lung Cancer. J Trans/ Med, 13, 113.

42. Ivanova, E., Canovas, S., Garcia-Martinez, S., Romar, R., Lopes, J.S., Rizos, D., Sanchez-Calabuig, M.J., Krueger, F., Andrews, S., Perez-Sanz, F.et al. (2020) DNA methylation changes during preimplantation development reveal inter-species differences and reprogramming events at imprinted genes. Clin Epigenetics, 12, 64.

43. Marcho, C., Cui, W. and Mager, J. (2015) Epigenetic dynamics during preimplantation development. Reproduction, 150, R109-120. 
44. Ankolkar, M., Patil, A., Warke, H., Salvi, V., Kedia Mokashi, N., Pathak, S. and Balasinor, N.H. (2012) Methylation analysis of idiopathic recurrent spontaneous miscarriage cases reveals aberrant imprinting at H19 ICR in normozoospermic individuals. Fertil Steril, 98, 1186-1192.

45. Zhang, Y., Hu, J.F., Wang, H., Cui, J., Gao, S., Hoffman, A.R. and Li, W. (2017) CRISPR Cas9-guided chromatin immunoprecipitation identifies miR483 as an epigenetic modulator of IGF2 imprinting in tumors. Oncotarget, 8, 34177-34190.

46. Chen, N., Yan, X., Zhao, G., Lv, Z., Yin, H., Zhang, S., Song, W., Li, X., Li, L., Du, Z.et al. (2018) A novel FLI1 exonic circular RNA promotes metastasis in breast cancer by coordinately regulating TET1 and DNMT1. Genome Biol, 19, 218.

47. Pian, L., Wen, X., Kang, L., Li, Z., Nie, Y., Du, Z., Yu, D., Zhou, L., Jia, L., Chen, N. et al. (2018) Targeting the IGF1R Pathway in Breast Cancer Using Antisense IncRNA-Mediated Promoter cis Competition. Mol Ther Nucleic Acids, 12, 105-117.

\section{Tables}

Table 1. Loss of $H 19$ and IGF2 imprinting in miscarriage decidua 


\begin{tabular}{lllll} 
& H19 & \multicolumn{2}{c}{ IGF2 } \\
\hline Cases (ID) & Genotype & cDNA & Genotype & cDNA
\end{tabular}

Loss of imprinting of $H 19(9.5 \%)$ *

\begin{tabular}{llllll}
\hline 1 & U18 & A/B & a/b & A/B & $\mathrm{b}$ \\
\hline 2 & U21 & A/B & a/b & B/B & - \\
\hline \multicolumn{7}{l}{ Loss of imprinting of $/ G F 2$} & $(35 \%)^{\star *}$ \\
\hline 1 & 8 & A/B & a & A/B & a/b \\
\hline 2 & E1 & A/B & b & A/B & a/b \\
\hline 3 & E3 & A/A & - & A/B & a/b \\
\hline 4 & E5 & A/B & b & A/B & a/b \\
\hline 5 & U11 & A/A & - & A/B & a/b \\
\hline 6 & U14 & A/A & - & A/B & a/b \\
\hline 7 & U17 & A/A & - & A/B & a/b
\end{tabular}

Loss of imprinting of $H 19$ and $/ G F 2^{* * *}$

\begin{tabular}{llllll}
\hline 1 & M22 & A/B & a/b & A/B & a/b \\
\hline 2 & U20 & A/B & a/b & A/B & a/b
\end{tabular}

* After genotyoing, 21 informative samples were used for $\mathrm{H} 19$ allelic analysis

** 20 IGF2-informative samples were used to examine IGF2 imprinting

*** Informative for both $\mathrm{H} 19$ and IGF2

- Tissues that are not informative for allelic analysis of either H19 or IGF2

Figures 


\section{A. LncRNA profiling}

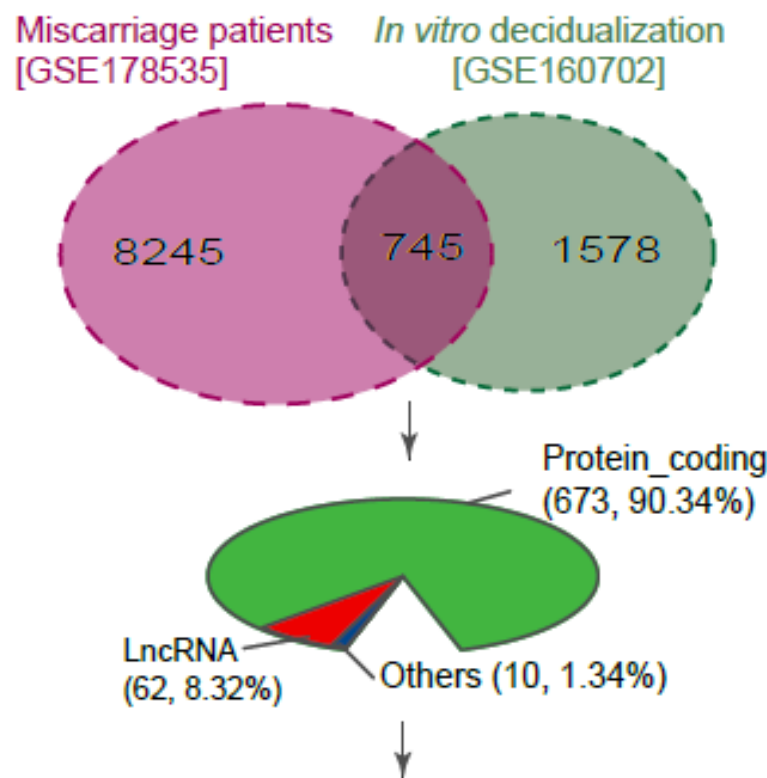

62 differentially expressed IncRNAs

\section{B. KEGG pathway}

Signaling pathways regulating pluripotency of stem cells

Proteoglycans in cancer Basal cell carcinoma

Pathways in cancer

Cytokine-cytokine receptor interaction

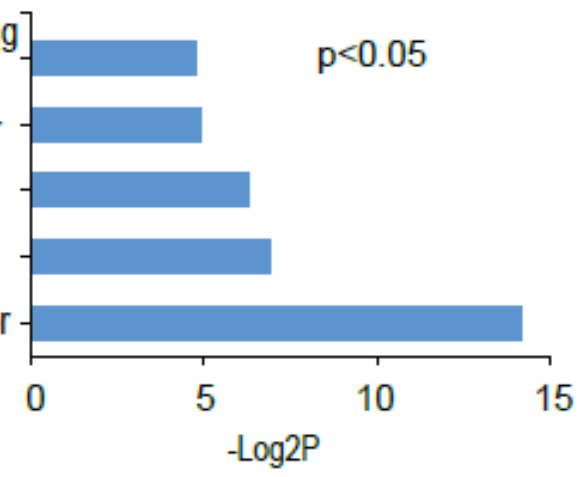

\section{Hierarchical cluster heatmap}

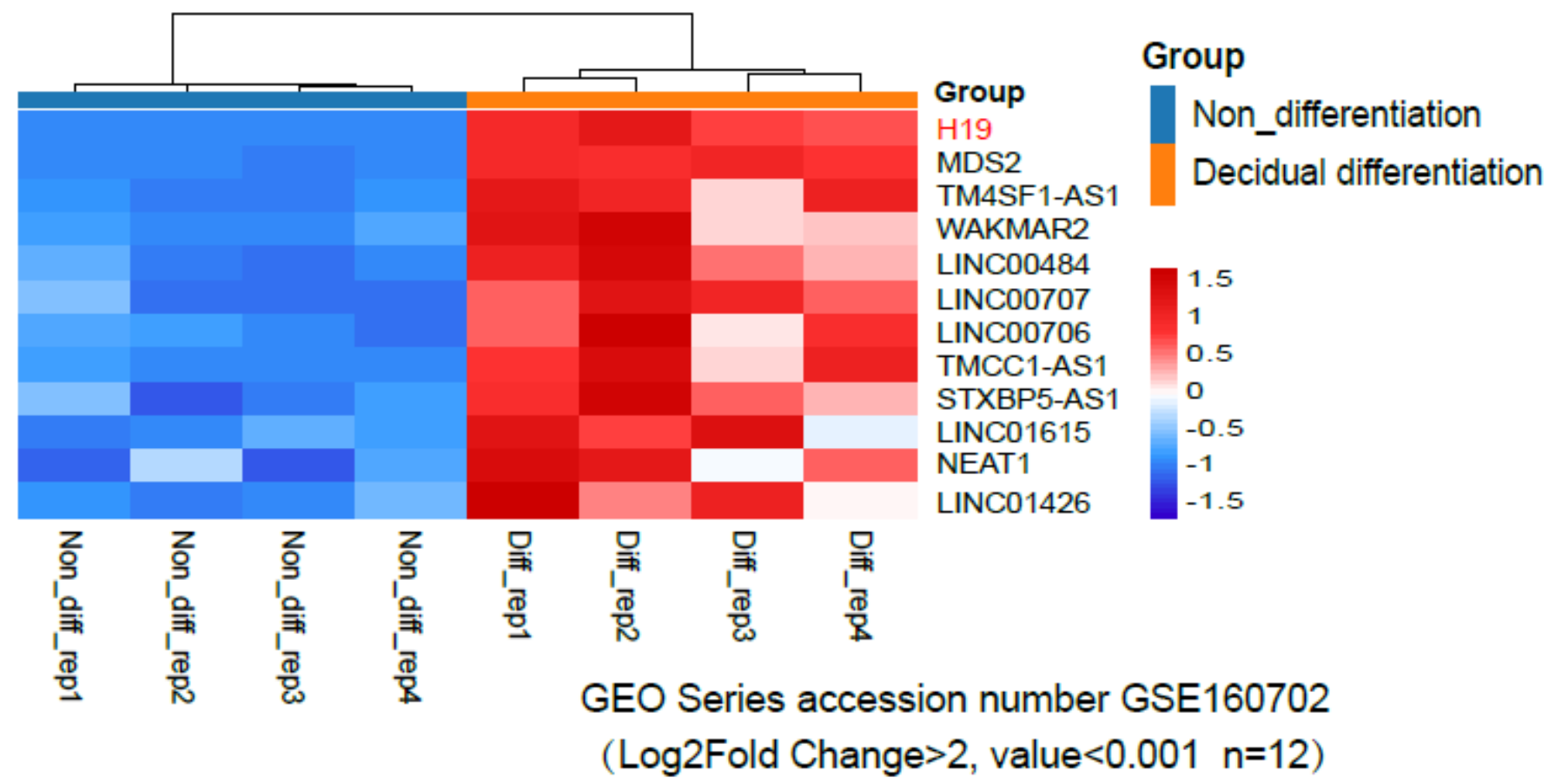

Figure 1

Differentially expressed IncRNAs in RSA patients by RNA-seq 


\section{A. H19 expression}

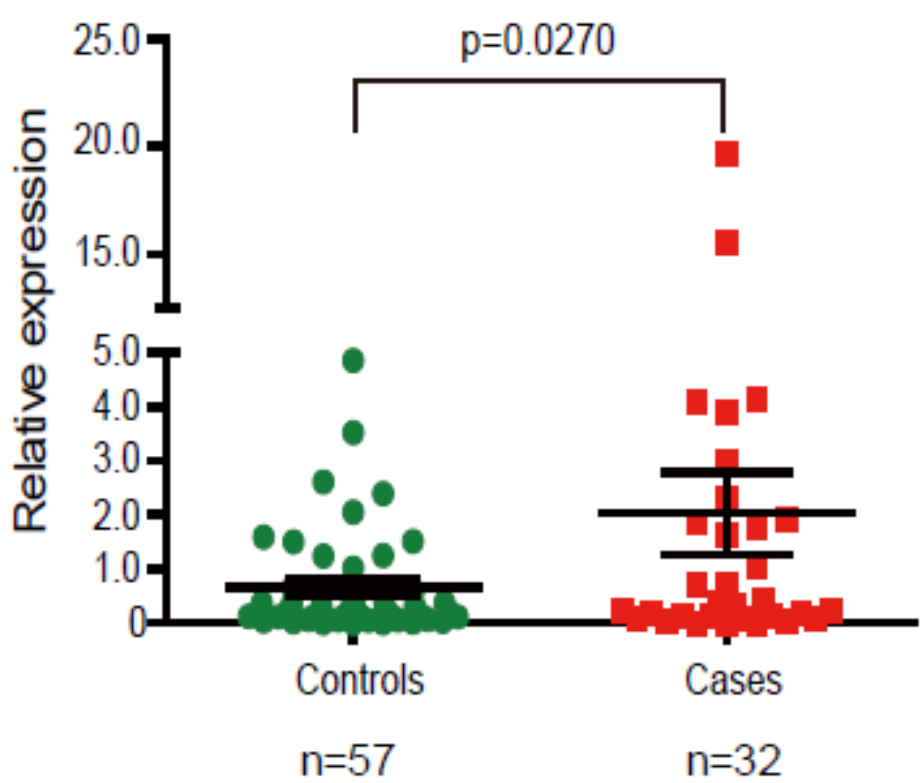

B. IGF2 expression

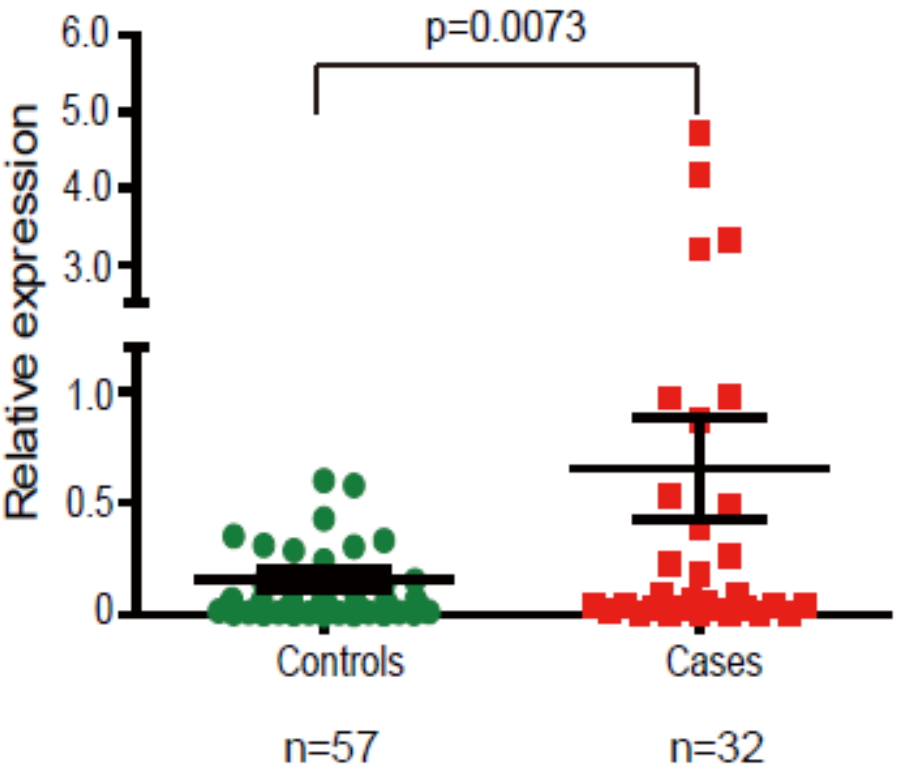

Figure 2

Upregulation of $\mathrm{H} 19$ and IGF2 in decidua of miscarriage patients 
A. Loss of imprinting

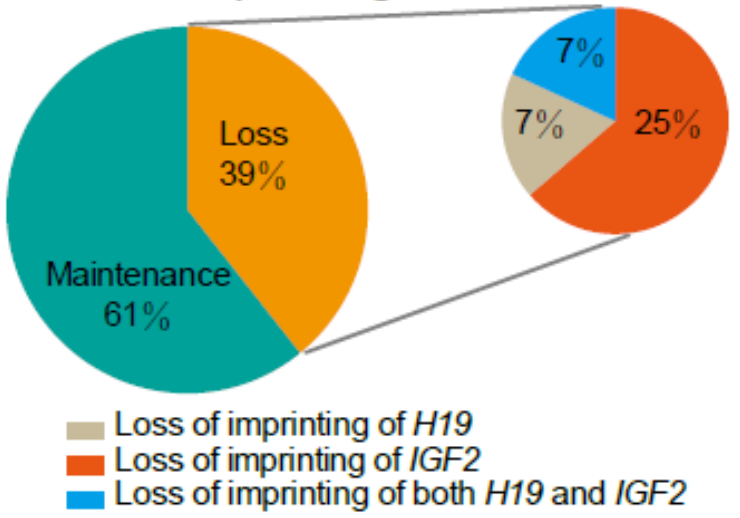

C. Imprinting of IGF2

\section{Control 4 gDNA}

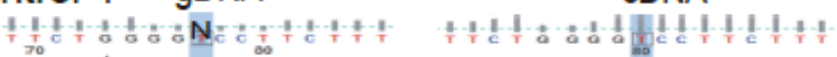
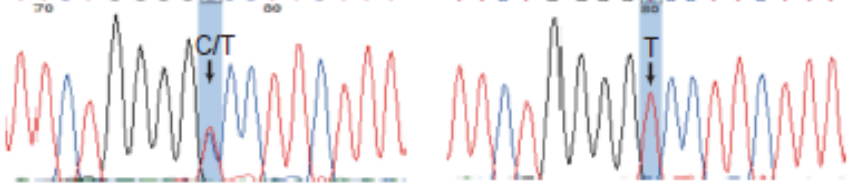

\section{Case U11}



Case M22

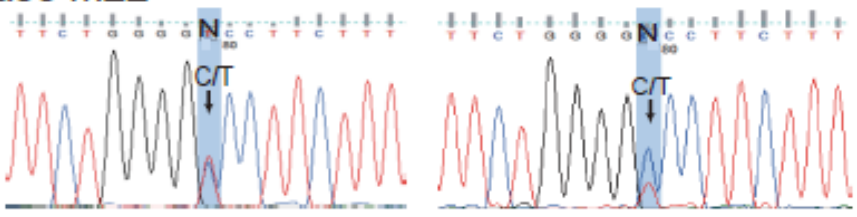

B. H19 imprinting

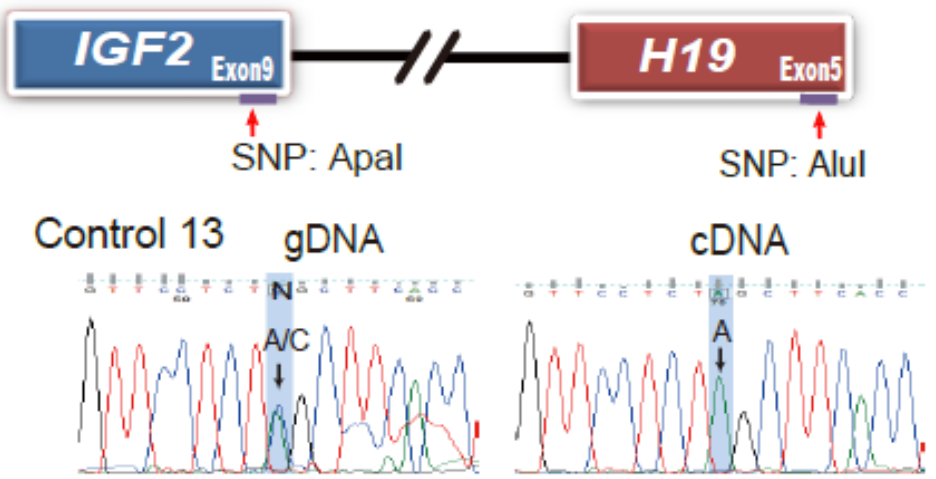

\section{Case U18}
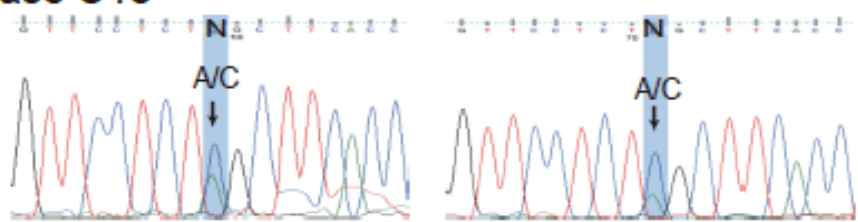

\section{Case M22}

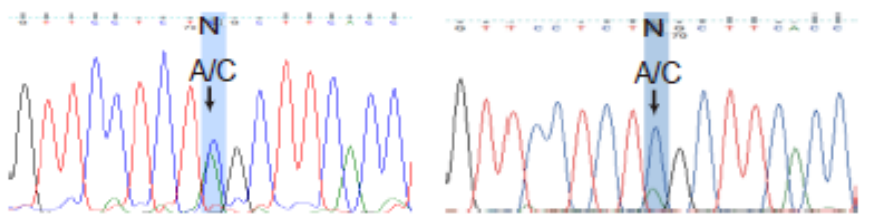

\section{Figure 3}

Loss of H19/IGF2 imprinting in decidual tissues of miscarriage cases. 
A. Drug-induced decidualization

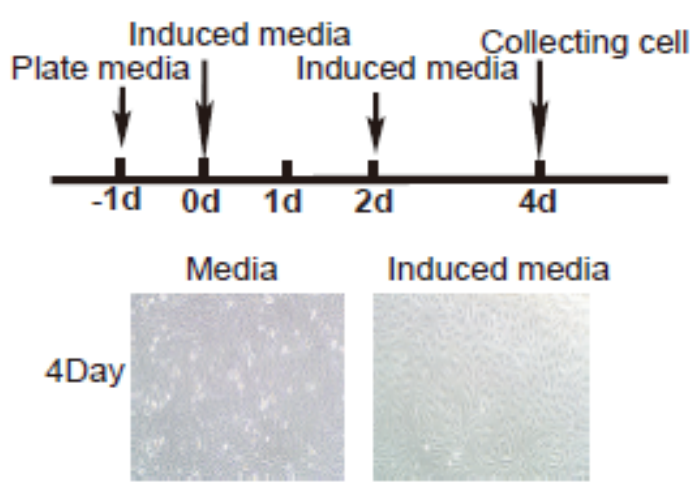

C. H19 and IGF2 expression

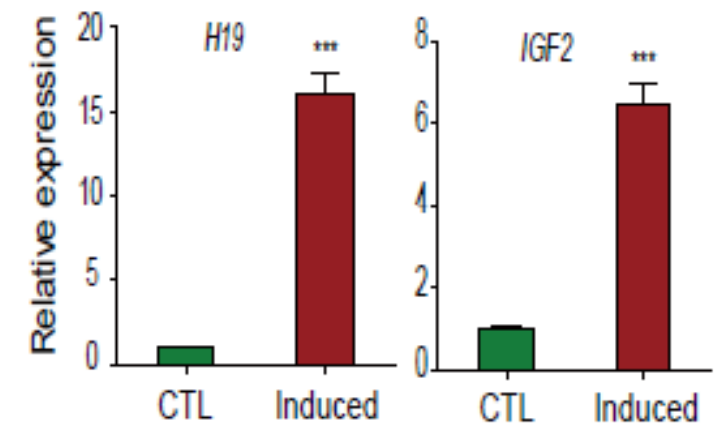

E. IGF2 Imprinting
B. Deciduation markers
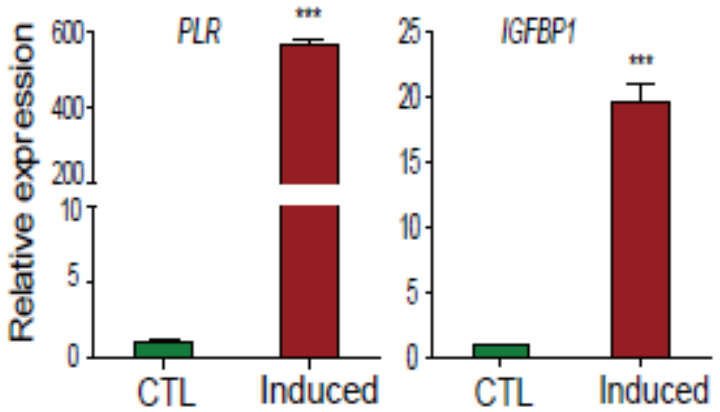

D. H19 Imprinting

CTL CDNA



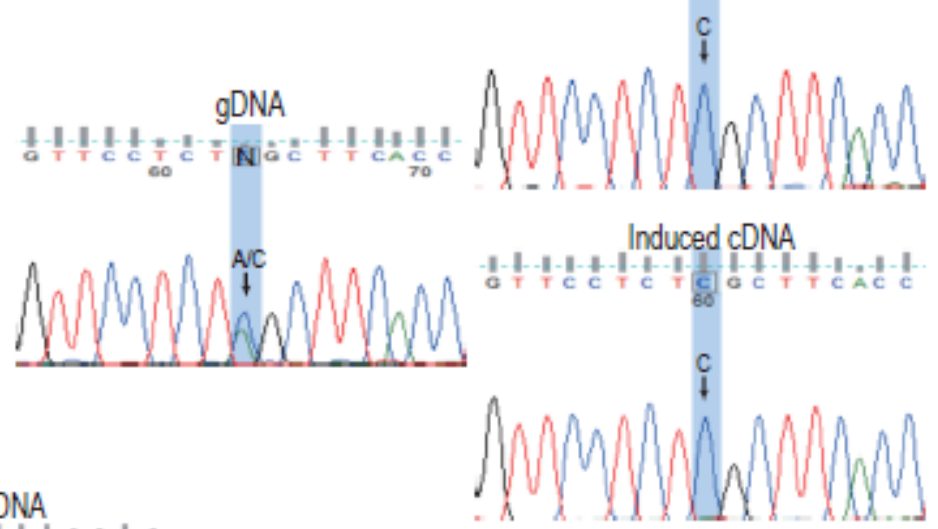

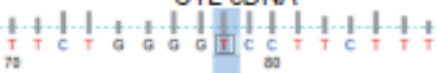


Figure 4

Aberrant H19/IGF2 expression in primary endometrial cells following drug-induced decidualization. 
A. ChIP primers

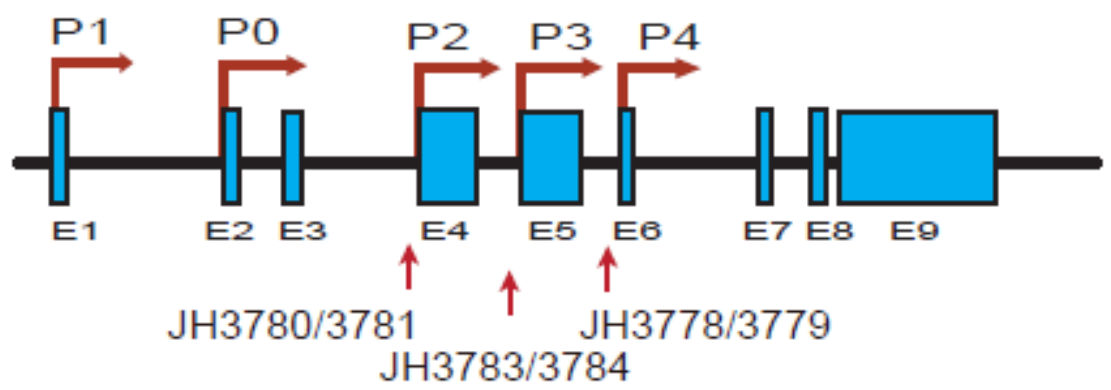

B. H3K27 methylation

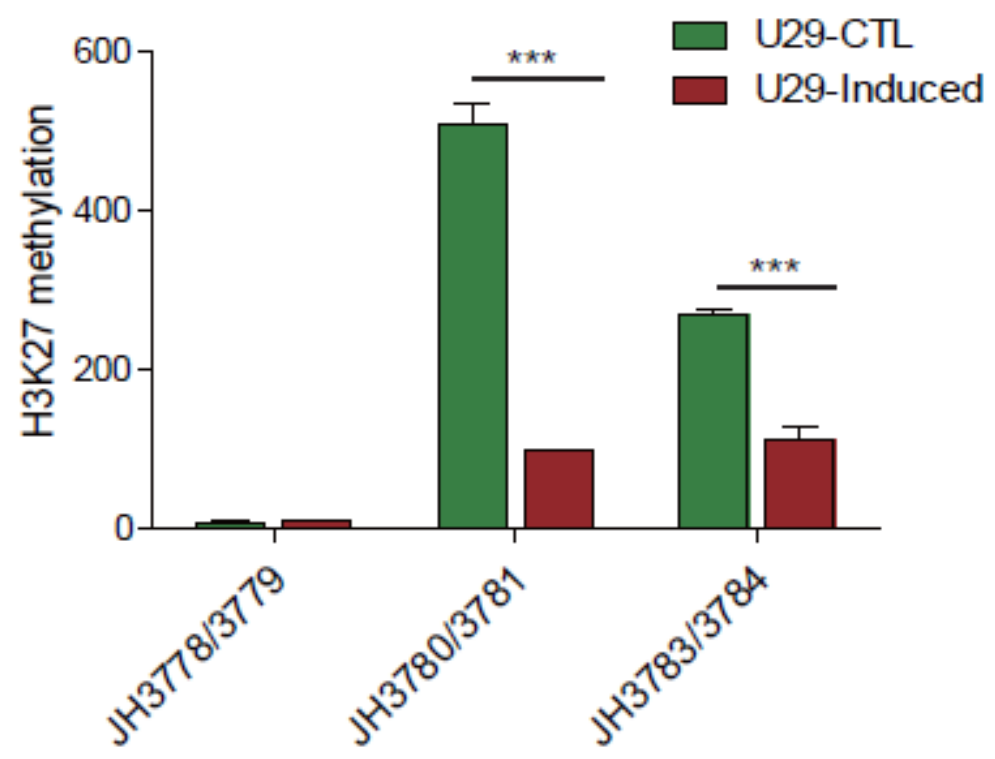

Figure 5

H3K27 methylation in the promoter of IGF2. 
A. CTCF-midiated introchromosomal loops in the H19/IGF2 locus

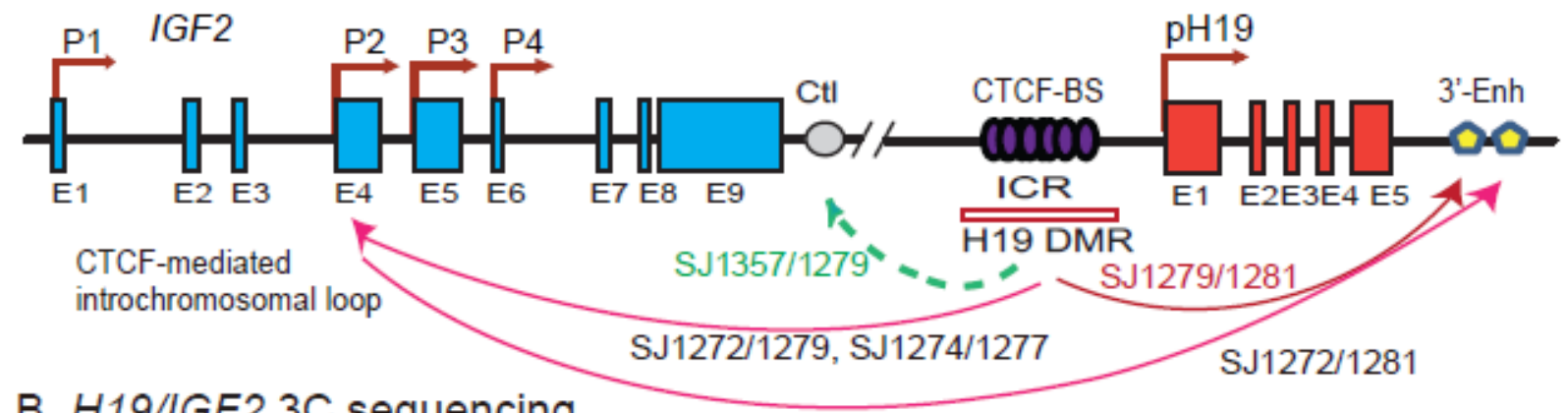

B. H19/IGF2 3C sequencing

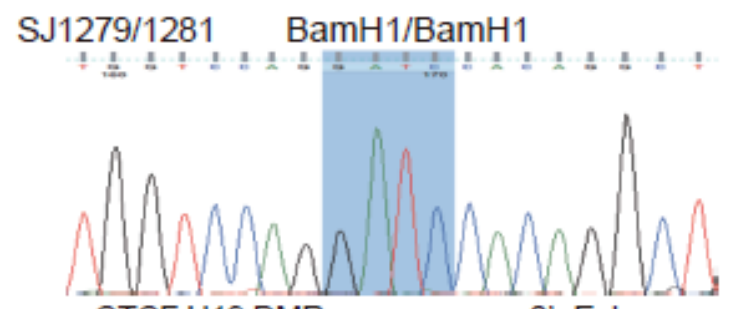

CTCF H19 DMR

SJ1272/1279

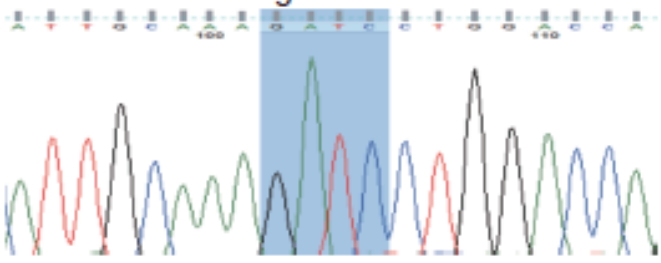

IGF2 promoter
3'- Enh

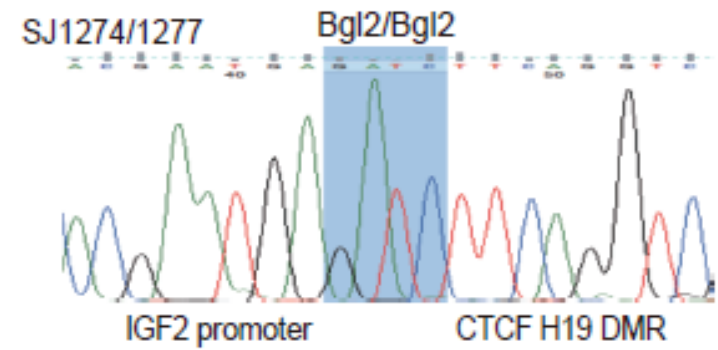

SJ1272/1281

$\mathrm{Bg} \mid 2 / \mathrm{BamH} 1$

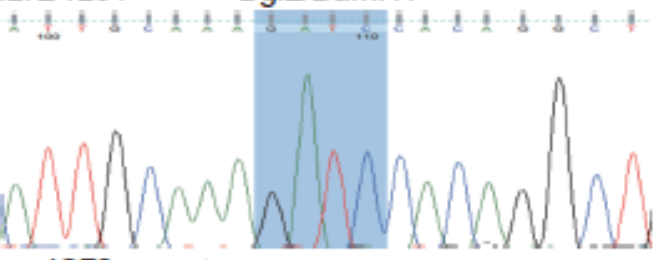

IGF2 promoter
3'- Enh

C. Intrachromosomal loop

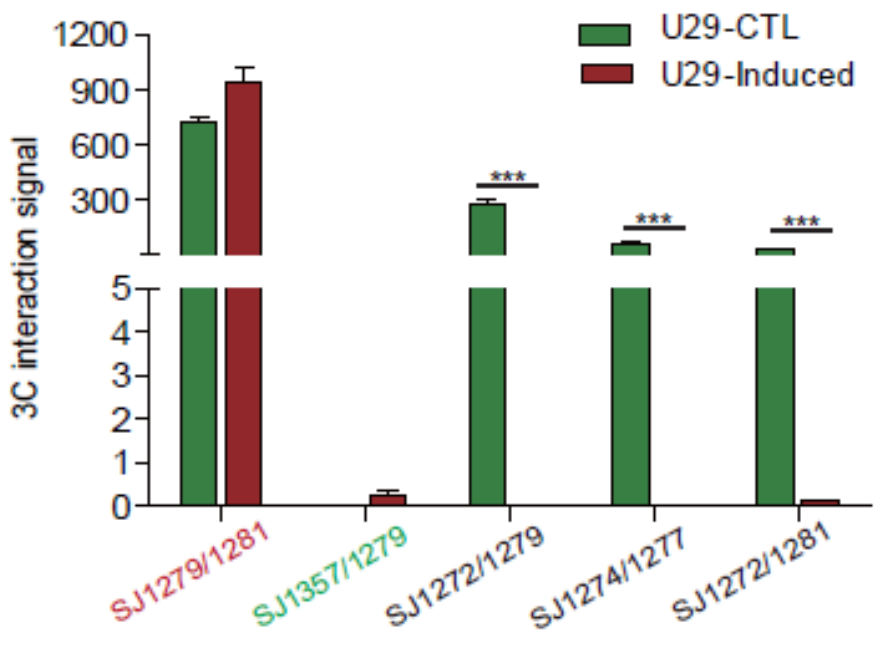

\section{Figure 6}

Intrachromosomal loop interactions in the H19/IGF2 imprinting locus. 
A. CTCF CPG sites in H19/IGF2 ICR

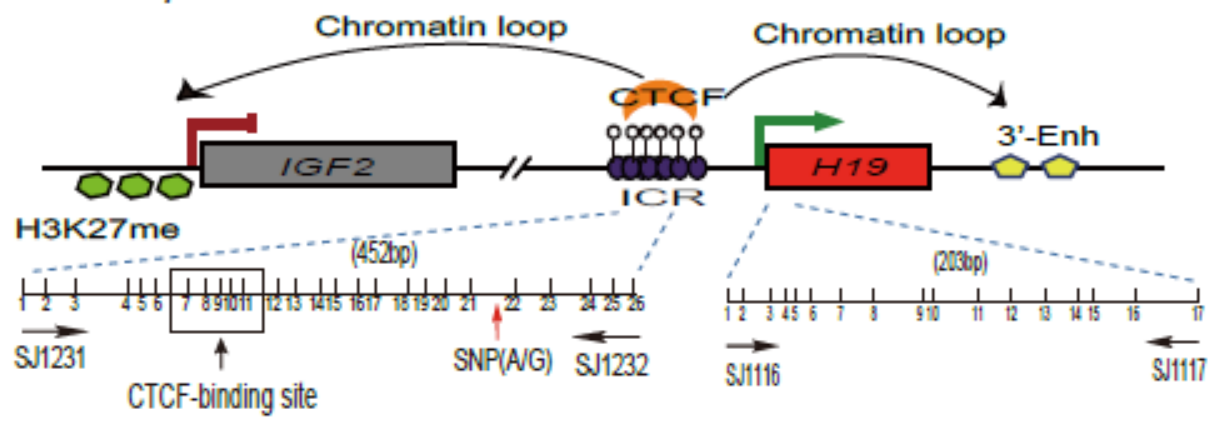

B. DNA methylation

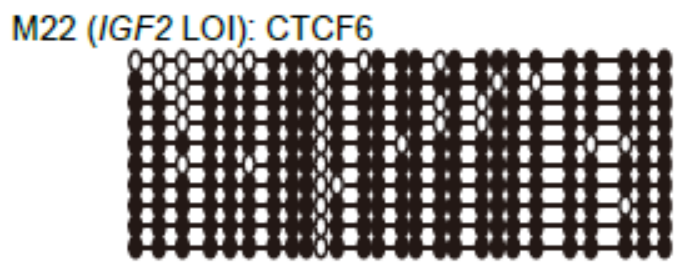

U11 (IGF2 LOI): CTCF6

AG alleleg-

$(36.5 \%)$

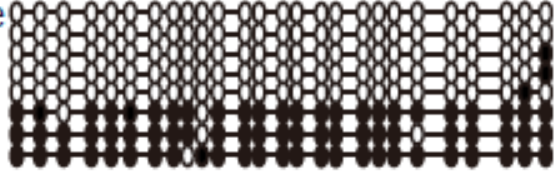

M22 (H19 LOI): H19 promoter

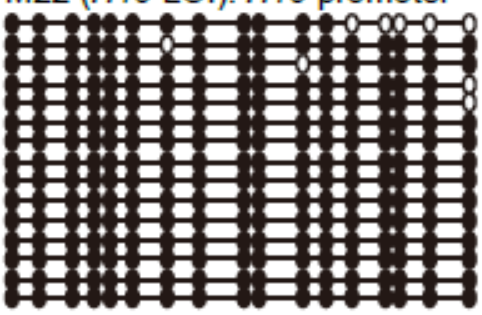

U11 (H19 NI): H19 promoter

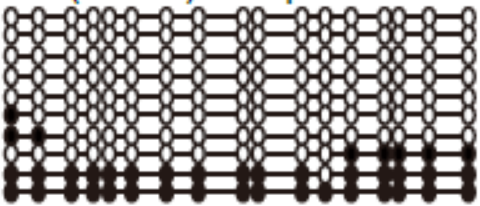

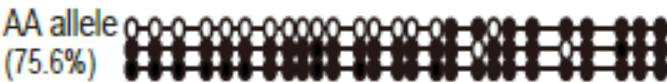

C. Aberrent imprinting in miscarriage



Figure 7

Abnormal DNA methylation in the imprinting control region (ICR)

\section{Supplementary Files}

This is a list of supplementary files associated with this preprint. Click to download. 
- WenH19Supplemnetalmaterials882021.pdf

Page 25/25 